\title{
Reproductive and Menopausal Factors and Risk of Second Primary Breast Cancer after In Situ Breast Carcinoma
}

\author{
Michelle L. Baglia ${ }^{1}$, Mei-Tzu C. Tang ${ }^{1}$, Kathleen E. Malone ${ }^{1}$, Peggy Porter ${ }^{1}$, and Christopher \\ I. $\mathbf{L i}^{1}$ \\ ${ }^{1}$ Division of Public Health Sciences, Fred Hutchinson Cancer Research Center, Seattle, WA
}

\begin{abstract}
Purpose: In situ breast cancer patients have a higher risk of developing a second primary breast cancer than women in the general population have of developing breast cancer. We have limited understanding of why some women with a previous in situ breast cancer develop second primary breast cancers while others do not.
\end{abstract}

Methods: In this population-based nested case-control study, we evaluated the association between reproductive and menopausal factors and risk of developing a second primary breast cancer among women with a previous in situ breast cancer. Using conditional logistic regression, these associations were evaluated in 552 cases and 1,032 individually matched controls.

Results: Older age at menarche was associated with risk of second primary breast cancer among women with a previous in situ breast cancer (compared to age <12, age 13: $\mathrm{OR}=0.60(0.42,0.85)$; age $\geq 14$ : OR=0.69 $\left.(0.47,1.00) ; P_{\text {trend }}=0.07\right)$. Breastfeeding for $>12$ months was associated with a decreased risk of developing a second primary breast cancer $(\mathrm{OR}=0.62(0.39,0.98))$. No associations were observed for other reproductive or menopausal factors evaluated.

Conclusions: Results from this study suggest that reproductive factors may play a role in development of a second primary breast cancer after diagnosis of in situ breast carcinoma.

\section{Keywords}

breast cancer; reproductive; in situ breast cancer; menopausal hormone therapy

\section{Introduction}

Approximately $20 \%$ of all incident breast cancers in the United States are in situ tumors; rates of in situ breast cancer have risen substantially with increased rates of mammography. $[1,2]$ Women with a previous in situ breast tumor are at an increased risk of developing a second in situ breast tumor or a second primary invasive breast cancer compared to women in the general population without a personal history of breast cancer.[3-5] Several reproductive and menopausal factors have been shown to be associated with risk of in situ breast carcinoma and/or invasive breast cancer, including age at menarche,[6,7] age at

Corresponding Author: Michelle L. Baglia, PhD, MPH, Division of Public Health Sciences, Fred Hutchinson Cancer Research Center, 1100 Fairview Ave. N., M4-C308, Seattle, WA 98109, mbaglia@ fredhutch.org, Telephone: 206-667-6736, Fax: 206-667-5948. 
menopause, $[6,8]$ parity,[9-11,7] age at first full-term pregnancy, $[9,10,12,7,11]$ duration of breastfeeding,[10,13] and use of exogenous hormones.[14-18,8,19,7] Few studies have assessed the relationships between these factors and risk of second primary breast cancer among women with a previous in situ breast cancer and those that have have found inconsistent results. In a study of 709 women with a previous ductal carcinoma in situ (DCIS), risk of second breast cancer was not significantly associated with age at menarche, nulliparity, age at first birth, or use of menopausal hormone therapy (mHT).[20] A more recent cohort study similarly found no association between $\mathrm{mHT}$ and risk of second breast cancer among 1,036 women with a previous DCIS.[21] However, these studies had relatively few second breast cancers in their populations (103 and 209, respectively).

We hypothesized that the associations between breast cancer risk factors and second primary breast cancer would be similar in direction to the association observed with first primary breast cancer. We evaluated the association between reproductive and menopausal factors and risk of developing a second in situ or invasive breast cancer using data from a nested case-control study of women with a previous in situ breast cancer.

\section{Materials and Methods}

Using data from a previously described population-based nested case-control study among women with a previously diagnosed in situ breast carcinoma (either ductal or lobular carcinoma in situ),[22] we evaluated reproductive and menopausal factors associated with risk of second primary breast cancer. Briefly, women aged 30-79 diagnosed between January 1, 1995 and June 30, 2013 with in situ breast carcinoma in western Washington State were eligible for the study. Cases $(n=573)$ were women who developed a second primary breast cancer more than 6 months following their first in situ breast cancer diagnosis. Controls $(n=1,096)$ were women who did not develop a second primary breast cancer during the study and were matched individually $2: 1$ to cases. The response rates for cases and controls were $69.5 \%$ and $56.2 \%$, respectively. Matching factors were age, year of initial in situ breast carcinoma diagnosis, county of residence at diagnosis, surgical and radiation treatment, histology and grade of initial in situ breast tumor. The study was approved by the Institutional Review Board (IRB) at the Fred Hutchinson Cancer Research Center.

\section{Data Collection}

Information on demographic, epidemiologic, and clinical factors was collected via a telephone questionnaire administered by trained interviewers and additional data on tumor characteristics, treatment, and breast cancer risk factors were collected through medical record review. Data were collected for the period prior to the first diagnosis up through the reference date, which, for cases, was the date of second primary breast cancer and, for controls, an assigned reference date. Data on reproductive and menopausal factors were obtained from both interview and medical records. Specifically, women were asked about their reproductive history, including pregnancy and breastfeeding history and timing of menarche and menopause, and history of use of oral contraceptives. Data on parity and age at first pregnancy were also abstracted from medical records. For patients who were deceased at the time of this study, data was collected from medical records. Questionnaires 
served as the primary source of data and were supplemented with data from medical records when questionnaire data were missing. Our study focused on the status of reproductive and menopausal factors at the time of the first diagnosis as many of the factors occurred prior to the first diagnosis. Participants were excluded from analysis if they were missing data on all reproductive and menopausal variables of interest (21 case-control pairs ( $\mathrm{n}=21$ cases and 37 controls) and 27 additional controls (where the case had other control(s) with data available)). Our final sample included 552 cases and 1,032 controls available for analysis.

\section{Statistical Analysis}

Odds ratios (ORs) and corresponding 95\% confidence intervals (CIs) were calculated to assess the associations between reproductive and menopausal factors and risk of second primary breast cancer, overall and among invasive cases only, using conditional logistic regression. Matching factors were implicitly adjusted for in the analyses. Breastfeeding duration analyses were adjusted for number of full-term pregnancies. Other variables, including known breast cancer risk factors (race/ethnicity, family history of breast cancer, and body mass index (BMI), were evaluated as potential confounders but inclusion of these factors did not materially change our estimates. Effect modification by menopausal status, ER status, and other tumor characteristics was evaluated. Where applicable, p-values for trend tests were calculated using continuous variables. For analyses on menopausal hormone therapy use, only women who were postmenopausal at first diagnosis were included. Analyses were conducted using SAS v9.3 (SAS Institute, Cary, NC).

\section{Results}

Cases were more likely to have a family history of breast cancer and to be overweight or obese at the first in situ breast cancer diagnosis and reference compared to controls (Table 1). Cases were similar to controls on menopausal status, in situ tumor grade, and in situ treatments. The majority of cases developed a second breast cancer that was invasive (68\%, $\mathrm{n}=378$ ). With respect to laterality, $55 \%$ of the second breast cancers among cases were contralateral, $(n=304), 44 \%$ were ipsilateral $(n=244)$, and $1 \%$ were bilateral $(n=4)$.

Older age at menarche was associated with a reduced risk of second primary breast cancer among women with in situ breast cancer and a moderate trend was observed (compared to those <12, age 12: $\mathrm{OR}=0.79,95 \%$ CI: $0.55,1.14$; age $13: \mathrm{OR}=0.60,95 \%$ CI: $0.42,0.85$; age 214: OR=0.69, 95\% CI: 0.47, 1.00; $P_{\text {tren }}=0.07$ ) (Table 2). After adjustment for number of full-term pregnancies, breastfeeding for more than 12 months was associated with a decreased risk of developing a second primary breast cancer ( $\mathrm{OR}=0.62,95 \% \mathrm{CI}: 0.39,0.98)$. This association was stronger among cases who developed a second invasive cancer $(\mathrm{OR}=0.52,95 \%$ CI: $0.30,0.90)$. However, a trend was not observed among all cases or invasive cases and breastfeeding (yes/no) was not associated with second primary breast cancer. Menopausal hormone therapy use at $1^{\text {st }}$ diagnosis was significantly inversely associated with risk of second primary breast cancer, particularly among invasive cases $(\mathrm{OR}=0.66,95 \%$ CI: $0.46,0.95)$. This inverse association was stronger among those taking combination estrogen and progestin ( $\mathrm{OR}=0.58,95 \% \mathrm{CI}$ : $0.37,0.92)$ than among those taking unopposed estrogen $(\mathrm{OR}=0.73,95 \% \mathrm{CI}$ : $0.48,1.11)$. No associations between age at first 
full-term pregnancy, number of full-term pregnancies, use of hormonal birth control in two years prior to first breast cancer diagnosis, or age at menopause and risk of second primary breast cancer among women with a previous in situ breast cancer were observed.

When stratified by ER status of the second breast cancer (Table 3), the association with breastfeeding (ever/never) was observed among women whose second breast cancer was ER-(OR=0.35, 95\% CI: 0.14, 0.87) but not $\mathrm{ER}+(\mathrm{OR}=0.89,95 \%$ CI: $0.58,1.35)$, although a test of heterogeneity by ER status was not statistically significant (ER- compared to ER+: $\mathrm{OR}=0.56,95 \% \mathrm{CI}: 0.29,1.09, p=0.09)$. Age at menopause was moderately inversely associated with risk of second primary breast cancer among women whose second tumor was $\mathrm{ER}+(\mathrm{OR}=0.97,95 \% \mathrm{CI}: 0.94,1.00)$. Current $\mathrm{mHT}$ use at $1^{\text {st }}$ diagnosis was inversely associated with risk of second primary breast cancer among women whose second tumor was $\mathrm{ER}+(\mathrm{OR}=0.68,95 \% \mathrm{CI}: 0.47,0.99)$, particularly among those who took combination estrogen and progestin $(\mathrm{OR}=0.63,95 \% \mathrm{CI}: 0.40,1.00)$. A statistically significant association was not observed among women whose second tumor was ER-. No other significant associations were observed by ER status.

When stratified by menopausal status, older age at first full-term pregnancy was associated with a moderate increase in risk of second primary invasive breast cancer among premenopausal women (per year: $\mathrm{OR}=1.05,95 \% \mathrm{CI}: 0.99,1.11$ ) and a moderate decrease in risk among postmenopausal women (per year: $\mathrm{OR}=0.97,95 \% \mathrm{CI}$ : $0.92,1.01$ ), which was suggestive of an interaction $\left(P_{\text {interaction }}=0.06\right)$. No other differences by menopausal status were observed. We also considered these associations according to features of the initial in situ tumor. When stratified by in situ breast carcinoma grade, women with a grade 4 (undifferentiated) in situ breast carcinoma who were aged 30 or older at first full-term pregnancy were more likely to develop a second breast cancer (OR=3.41, 95\% CI: 1.15 , 10.15); no association between age at first full-term pregnancy and risk of developing a second breast cancer was observed among women with in situ breast tumors grade $1 / 2$ or grade 3 .

Differences in risk were not observed when the results were stratified by laterality of the second breast cancer or in situ breast carcinoma histology/presence of comedo necrosis (data not shown).

\section{Discussion}

Our results suggest that older age at menarche and breastfeeding duration may be associated with reduced risks of developing a second primary breast cancer among women with a previous in situ breast cancer diagnosis, but that other reproductive factors are not. Current menopausal hormone therapy at $1^{\text {st }}$ diagnosis was inversely associated with risk of second primary breast cancer, particularly among those whose second primary breast cancer was ER + and invasive.

Previous studies have shown that later age at menarche is associated with a decreased risk of primary breast cancer.[6,7] Similarly, our results showed that later age at menarche was associated with a decreased risk of second primary breast cancer among women with a 
previous in situ breast cancer. Breastfeeding duration was associated with a decreased risk of second primary breast cancer among women with a previous in situ breast cancer, even after adjustment for number of full-term births, though a trend was not observed. Previous studies have shown that breastfeeding lowers the risk of first primary breast cancer which is consistent with the findings of our study.[13] Previous studies have also suggested that breastfeeding may particularly reduce the risk of triple-negative breast cancer.[23-25] Similarly, we found that the reduced risk of second primary breast cancer was stronger among those whose second breast cancer was ER-. It is likely that the same hormonal mechanisms involved in development of a first primary breast cancer are potentially relevant for development of a second primary breast cancer. However, we did not see an association between risk of second primary breast cancer among women with a previous in situ breast cancer and other established reproductive risk factors for breast cancer including age at first full-term pregnancy, parity, and age at menopause. This suggests that some risk factors for first and second primary breast cancer development may differ.

Our results showed that women who were currently taking menopausal hormone therapy at their $1^{\text {st }}$ in situ breast cancer diagnosis were less likely to develop second breast cancers. Previous studies have shown menopausal hormone therapy use, particularly combination estrogen and progestin therapy, increases the risk of breast cancer.[8] Our finding is likely due to hormone therapy being a key driver of the risk of the first in situ cancer, but with stoppage of use after this diagnosis resulting in a lower risk of a second cancer due to removal of the main etiologic driver. However, due to the small number of women in our study who used menopausal hormone therapy after their first diagnosis, we were unable to stratify our results to determine whether the observed association was present in both groups.

Strengths of our study include its population-based study design, comprehensive data collection, and number of second primary breast cancers in our study. To our knowledge, this is the largest study designed to evaluate risk factors for second breast cancer events among women with a personal history of in situ breast carcinoma. Potential recall bias is a limitation of the case-control study design used for this study, which may have been greater for women with first diagnoses earlier in the study period. Additionally, selection bias may have been introduced into our study through modest response rates. We did not collect data on screening frequency of participants in our study following their first diagnosis and are unable to determine whether screening rates were different among cases and controls.

Our results suggest that some reproductive factors, age at menarche and breastfeeding, may be risk factors for second primary breast cancer after diagnosis of in situ breast carcinoma. Further studies are needed to elucidate the association between traditional risk factors for primary breast cancer and risk of second primary breast cancer among women with a previous in situ breast cancer. These results are important for this growing population.

\section{Acknowledgments}

Financial support: This study was funded by the National Cancer Institute (R01-CA097271). Michelle Baglia is funded by T32-CA009168. 


\section{References}

1. American Cancer Society. Cancer Facts \& Figures 2017. Atlanta: American Cancer Society; 2017.

2. Li CI, Daling JR (2007) Changes in breast cancer incidence rates in the United States by histologic subtype and race/ethnicity, 1995 to 2004. Cancer Epidemiol Biomarkers Prev 16 (12):2773-2780. doi:10.1158/1055-9965.EPI-07-0546 [PubMed: 18086787]

3. Franceschi S, Levi F, La Vecchia C, Randimbison L, Te VC (1998) Second cancers following in situ carcinoma of the breast. Int J Cancer 77 (3):392-395 [PubMed: 9663601]

4. Soerjomataram I, Louwman WJ, van der Sangen MJ, Roumen RM, Coebergh JW (2006) Increased risk of second malignancies after in situ breast carcinoma in a population-based registry. $\mathrm{Br} \mathrm{J}$ Cancer 95 (3):393-397. doi:10.1038/sj.bjc.6603231 [PubMed: 16804522]

5. Warnberg F, Bergh J, Zack M, Holmberg L (2001) Risk factors for subsequent invasive breast cancer and breast cancer death after ductal carcinoma in situ: a population-based case-control study in Sweden. Cancer Epidemiol Biomarkers Prev 10 (5):495-499 [PubMed: 11352860]

6. Collaborative Group on Hormonal Factors in Breast C (2012) Menarche, menopause, and breast cancer risk: individual participant meta-analysis, including 118964 women with breast cancer from 117 epidemiological studies. Lancet Oncol 13 (11):1141-1151. doi:10.1016/ S1470-2045(12)70425-4 [PubMed: 23084519]

7. Trentham-Dietz A, Newcomb PA, Storer BE, Remington PL (2000) Risk factors for carcinoma in situ of the breast. Cancer Epidemiol Biomarkers Prev 9 (7):697-703 [PubMed: 10919740]

8. Breast cancer and hormone replacement therapy: collaborative reanalysis of data from 51 epidemiological studies of 52,705 women with breast cancer and 108,411 women without breast cancer. Collaborative Group on Hormonal Factors in Breast Cancer (1997). Lancet 350 (9084): 1047-1059 [PubMed: 10213546]

9. Lord SJ, Bernstein L, Johnson KA, Malone KE, McDonald JA, Marchbanks PA, Simon MS, Strom BL, Press MF, Folger SG, Burkman RT, Deapen D, Spirtas R, Ursin G (2008) Breast cancer risk and hormone receptor status in older women by parity, age of first birth, and breastfeeding: a casecontrol study. Cancer Epidemiol Biomarkers Prev 17 (7):1723-1730. doi: 10.1158/1055-9965.EPI-07-2824 [PubMed: 18628424]

10. Ma H, Bernstein L, Pike MC, Ursin G (2006) Reproductive factors and breast cancer risk according to joint estrogen and progesterone receptor status: a meta-analysis of epidemiological studies. Breast Cancer Res 8 (4):R43. doi:10.1186/bcr1525 [PubMed: 16859501]

11. Lambe M, Hsieh CC, Tsaih SW, Ekbom A, Trichopoulos D, Adami HO (1998) Parity, age at first birth and the risk of carcinoma in situ of the breast. Int J Cancer 77 (3):330-332 [PubMed: 9663590]

12. Bernstein L (2002) Epidemiology of endocrine-related risk factors for breast cancer. J Mammary Gland Biol Neoplasia 7 (1):3-15 [PubMed: 12160084]

13. Collaborative Group on Hormonal Factors in Breast C (2002) Breast cancer and breastfeeding: collaborative reanalysis of individual data from 47 epidemiological studies in 30 countries, including 50302 women with breast cancer and 96973 women without the disease. Lancet 360 (9328):187-195. doi:10.1016/S0140-6736(02)09454-0 [PubMed: 12133652]

14. Chlebowski RT, Kuller LH, Prentice RL, Stefanick ML, Manson JE, Gass M, Aragaki AK, Ockene JK, Lane DS, Sarto GE, Rajkovic A, Schenken R, Hendrix SL, Ravdin PM, Rohan TE, Yasmeen S, Anderson G, Investigators WHI (2009) Breast cancer after use of estrogen plus progestin in postmenopausal women. N Engl J Med 360 (6): 573-587. doi:10.1056/NEJMoa0807684 [PubMed: 19196674]

15. Chlebowski RT, Anderson GL, Gass M, Lane DS, Aragaki AK, Kuller LH, Manson JE, Stefanick ML, Ockene J, Sarto GE, Johnson KC, Wactawski-Wende J, Ravdin PM, Schenken R, Hendrix SL, Rajkovic A, Rohan TE, Yasmeen S, Prentice RL, Investigators WHI (2010) Estrogen plus progestin and breast cancer incidence and mortality in postmenopausal women. JAMA 304 (15): 1684-1692. doi:10.1001/jama.2010.1500 [PubMed: 20959578]

16. Hunter DJ, Colditz GA, Hankinson SE, Malspeis S, Spiegelman D, Chen W, Stampfer MJ, Willett WC (2010) Oral contraceptive use and breast cancer: a prospective study of young women. Cancer 
Epidemiol Biomarkers Prev 19 (10):2496-2502. doi:10.1158/1055-9965.EPI-10-0747 [PubMed: 20802021]

17. Collaborative Group on Hormonal Factors in Breast C (1996) Breast cancer and hormonal contraceptives: collaborative reanalysis of individual data on 53297 women with breast cancer and 100239 women without breast cancer from 54 epidemiological studies. Lancet 347 (9017):17131727 [PubMed: 8656904]

18. Breast cancer and hormonal contraceptives: further results. Collaborative Group on Hormonal Factors in Breast Cancer (1996). Contraception 54 (3 Suppl):1S-106S [PubMed: 8899264]

19. Nichols HB, Trentham-Dietz A, Egan KM, Titus-Ernstoff L, Hampton JM, Newcomb PA (2007) Oral contraceptive use and risk of breast carcinoma in situ. Cancer Epidemiol Biomarkers Prev 16 (11):2262-2268. doi:10.1158/1055-9965.EPI-07-0456 [PubMed: 18006914]

20. Habel LA, Daling JR, Newcomb PA, Self SG, Porter PL, Stanford JL, Seidel K, Weiss NS (1998) Risk of recurrence after ductal carcinoma in situ of the breast. Cancer Epidemiol Biomarkers Prev 7 (8):689-696 [PubMed: 9718221]

21. Kerlikowske K, Molinaro A, Cha I, Ljung BM, Ernster VL, Stewart K, Chew K, Moore DH, 2nd, Waldman F (2003) Characteristics associated with recurrence among women with ductal carcinoma in situ treated by lumpectomy. J Natl Cancer Inst 95 (22):1692-1702 [PubMed: 14625260]

22. Baglia ML, Tang MC, Malone KE, Porter P, Li CI (2018) Family History and Risk of Second Primary Breast Cancer after In Situ Breast Carcinoma. Cancer Epidemiol Biomarkers Prev. doi: 10.1158/1055-9965.EPI-17-0837

23. Islami F, Liu Y, Jemal A, Zhou J, Weiderpass E, Colditz G, Boffetta P, Weiss M (2015)

Breastfeeding and breast cancer risk by receptor status--a systematic review and meta-analysis. Ann Oncol 26 (12):2398-2407. doi:10.1093/annonc/mdv379 [PubMed: 26504151]

24. Shinde SS, Forman MR, Kuerer HM, Yan K, Peintinger F, Hunt KK, Hortobagyi GN, Pusztai L, Symmans WF (2010) Higher parity and shorter breastfeeding duration: association with triplenegative phenotype of breast cancer. Cancer 116 (21):4933-4943. doi:10.1002/cncr.25443 [PubMed: 20665494]

25. Palmer JR, Viscidi E, Troester MA, Hong CC, Schedin P, Bethea TN, Bandera EV, Borges V, McKinnon C, Haiman CA, Lunetta K, Kolonel LN, Rosenberg L, Olshan AF, Ambrosone CB (2014) Parity, lactation, and breast cancer subtypes in African American women: results from the AMBER Consortium. J Natl Cancer Inst 106 (10). doi:10.1093/jnci/dju237 


\section{Table 1}

Demographic and Clinical Factors by Case-Control Status

Study Participants (N(\%))

Characteristics
Age at 1st breast cancer diagno
$<50$
$50-59$
$60-69$
$70-79$
Year of 1st breast cancer diagnosis
1995-1997
1998-2000
2001-2004
2005-2013
Race/Ethnicity
Non-Hispanic white
Hispanic white
Black
Asian/Pacific Islander
Native American
Unknown

Family history of breast cancer

$\begin{array}{lcc}\text { Yes } & 265(26.4) & 173(32.3) \\ \text { No } & 740(73.6) & 362(67.7) \\ \text { Missing } & 27 & 17\end{array}$

BMI at 1st breast cancer diagnosis

$<25$

$25-<30$

$\geq 30$

Unknown

Grade of 1st tumor

1 - well differentiated

2 - moderately differentiated

3 - poorly differentiated

4 - undifferentiated

Unknown

Radiation treatment for 1 st breast cancer

Yes

No

Surgery for 1st breast cancer
Controls $(n=1,032) \quad$ Cases $(n=552)$

$\begin{array}{cc}355(34.4) & 194(35.1) \\ 361(35.0) & 187(33.9) \\ 218(21.1) & 113(20.5) \\ 98(9.5) & 58(10.5)\end{array}$

$\begin{array}{cc}226(21.9) & 116(21.0) \\ 225(21.8) & 144(26.1) \\ 292(28.3) & 142(25.7) \\ 289(28.0) & 150(27.2) \\ & \\ 935(90.6) & 489(88.6) \\ 19(1.8) & 12(2.2) \\ 17(1.7) & 13(2.4) \\ 47(4.6) & 29(5.3) \\ 14(1.4) & 8(1.5) \\ 0 & 1\end{array}$

1

$\begin{array}{cc}500(50.0) & 223(42.2) \\ 290(29.0) & 161(30.4) \\ 210(21.0) & 145(27.4) \\ 32 & 23 \\ 21(2.8) & 18(4.6) \\ 232(30.9) & 103(26.5) \\ 231(30.7) & 116(29.9) \\ 268(35.6) & 151(38.9) \\ 280 & 164\end{array}$

$\begin{array}{ll}495(48.0) & 255(46.2) \\ 537(52.0) & 297(53.8)\end{array}$

$32(3.1) \quad 24(4.4)$

$722(70.0) \quad 382(69.2)$ 
Study Participants (N(\%))

Characteristics

Controls $(n=1,032) \quad$ Cases $(n=552)$

Lumpectomy with sentinal node biopsy

$50(4.8)$

26 (4.7)

Lumpectomy with nodal dissection

$36(3.5)$

$19(3.4)$

Mastectomy

$192(18.6)$

$101(18.3)$

Laterality of 2nd breast cancer

Ipsilateral

Contralateral

Bilateral

n/a $\quad 244(44.2)$

$\mathrm{n} / \mathrm{a} \quad 304(55.1)$

$\mathrm{n} / \mathrm{a} \quad 4(0.7)$

Menopausal status at 1st breast cancer diagnosis

Pre/Peri-menopausal

$402(40.2) \quad 223(41.5)$

Postmenopausal

$598(59.8)$

$314(58.5)$

Unknown

32

15

Menopausal status at reference

Pre/Peri-menopausal

184 (18.6)

$111(21.1)$

Postmenopausal

805 (81.4)

$415(78.9)$

Unknown

43

26 
Table 2

Relationship between Reproductive and Menopausal Factors and Risk of Second Breast Cancer

Controls All Cases Invasive Cases

\begin{tabular}{|c|c|c|c|c|c|}
\hline & $\mathbf{n}(\%)$ & $\mathbf{n}(\%)$ & OR $(95 \% \mathrm{CI})^{1}$ & $\mathbf{n}(\%)$ & OR $(95 \% \mathrm{CI})^{1}$ \\
\hline \multicolumn{6}{|l|}{ Age at menarche } \\
\hline$<12$ & $142(16.2)$ & $101(22.6)$ & $1[\operatorname{Ref}]$ & $70(23.4)$ & $1[\operatorname{Ref}]$ \\
\hline 12 & $232(26.4)$ & $116(26.0)$ & $0.79(0.55,1.14)$ & $73(24.4)$ & $0.77(0.49,1.21)$ \\
\hline 13 & $290(33.0)$ & $122(27.3)$ & $0.60(0.42,0.85)$ & $91(30.4)$ & $0.66(0.43,1.01)$ \\
\hline$\geq 14$ & $214(24.4)$ & $108(24.2)$ & $0.69(0.47,1.00)$ & 65 (21.7) & $0.63(0.39,1.01)$ \\
\hline Continuous (1-year) & & & $0.93(0.85,1.01)$ & & $0.93(0.83,1.03)$ \\
\hline$P_{\text {trend }}$ & & & 0.07 & & 0.14 \\
\hline
\end{tabular}

Age at 1st full-term pregnancy ${ }^{2}$

$<20$

20-24

25-29

$30+$

Continuous (1-year)

$P_{\text {trend }}$

105 (13.8)

$292(38.4)$

$207(27.2)$

$156(20.5)$

$60(14.8)$

$157(38.7)$

$1.27(0.81,1.99)$

1 [Ref]

$100(24.6) \quad 0.99(0.69,1.41)$

$89(21.9)$

$1.12(0.76,1.66)$

$1.00(0.97,1.03)$

0.99

Number of full-term pregnancies

$\begin{array}{lccccc}\text { Nulliparous } & 218(21.3) & 118(21.4) & 1[\text { Ref] } & 79(21.2) & 1[\text { Ref] } \\ \text { Parous } & 807(78.7) & 433(78.6) & 0.99(0.76,1.29) & 298(79.1) & 1.00(0.73,1.38) \\ 1 & 155(15.2) & 91(16.7) & 1.16(0.81,1.66) & 54(14.5) & 1.06(0.68,1.66) \\ 2 & 359(35.2) & 171(31.4) & 0.85(0.63,1.15) & 124(33.2) & 0.94(0.65,1.36) \\ \geq 3 & 289(28.3) & 165(30.3) & 1.04(0.75,1.43) & 116(31.1) & 1.02(0.69,1.49)\end{array}$

Ever breast fed $^{2}$

$\begin{array}{lccccc}\text { No } & 161(23.4) & 84(24.4) & 1[\operatorname{Ref}] & 58(25.2) & 1[\text { Ref] } \\ \text { Yes } & 526(76.6) & 260(75.6) & 0.74(0.51,1.05) & 172(74.8) & 0.68(0.44,1.04)\end{array}$

Breast feeding duration (in months) ${ }^{2,3}$

\begin{tabular}{lccccc} 
Never & $161(23.5)$ & $84(24.6)$ & $1[\mathrm{Ref}]$ & $58(25.2)$ & $1[\mathrm{Ref}]$ \\
$<6$ & $197(28.8)$ & $92(26.9)$ & $0.72(0.48,1.07)$ & $61(26.5)$ & $0.69(0.42,1.13)$ \\
$6-12$ & $115(16.8)$ & $66(19.3)$ & $0.82(0.50,1.34)$ & $44(19.1)$ & $0.88(0.49,1.59)$ \\
$>12$ & $211(30.9)$ & $100(29.2)$ & $0.62(0.39,0.98)$ & $67(29.1)$ & $0.52(0.30,0.90)$ \\
Every 6 months & & & $0.99(0.93,1.06)$ & & $0.98(0.90,1.06)$ \\
\multicolumn{1}{r}{$P_{\text {trend }}$} & & & 0.79 & & 0.60
\end{tabular}

Use of hormonal birth control in 2 years prior to 1st breast cancer diagnosis

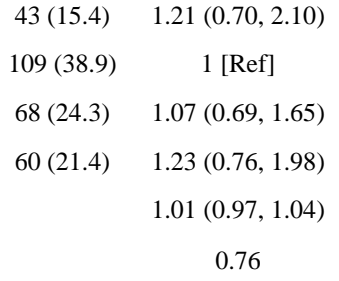

0.60

\begin{tabular}{|c|c|c|c|c|c|}
\hline No & $935(92.0)$ & $495(92.2)$ & $1[\mathrm{Ref}]$ & $342(93.2)$ & 1 [Ref] \\
\hline Yes & $81(8.0)$ & $42(7.8)$ & $0.94(0.62,1.42)$ & $25(6.8)$ & $0.96(0.56,1.66)$ \\
\hline \multicolumn{6}{|c|}{ Age at Menopause 4} \\
\hline$<45$ & $72(12.1)$ & $56(16.1)$ & $1[$ Ref $]$ & $39(16.3)$ & 1 [Ref] \\
\hline $45-49$ & $164(27.7)$ & $85(24.5)$ & $0.67(0.41,1.09)$ & 57 (23.9) & $0.71(0.39,1.26)$ \\
\hline
\end{tabular}




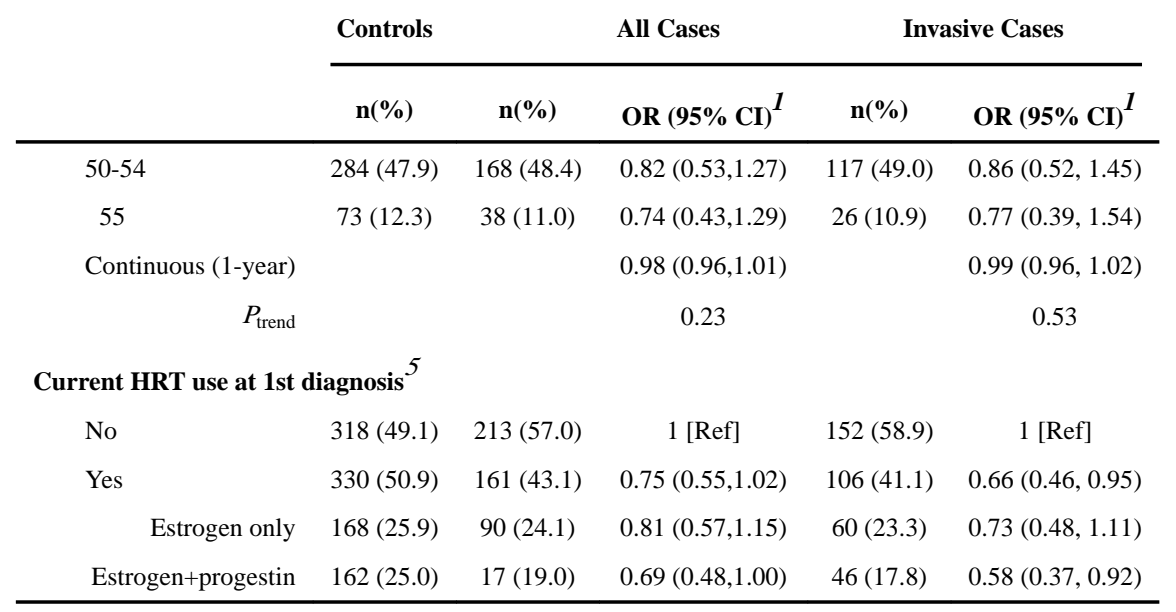

${ }^{1}$ Using conditional logistic regression, models were implicitly adjusted for the following matching factors: age, year of initial in situ breast carcinoma diagnosis, county of residence at diagnosis, surgical and radiation treatment, histology and grade of initial in situ breast tumor

${ }^{2}$ Among parous women

${ }^{3}$ Adjusted for number of full-term pregnancies

${ }^{4}$ Among postmenopausal women

${ }^{5}$ Among women who were postmenopausal prior to 1st diagnosis 
Table 3

Relationship between Reproductive and Menopausal Factors and Risk of Second Breast Cancer By ER Status of Second Breast Cancer

\begin{tabular}{|c|c|c|c|c|}
\hline & \multicolumn{2}{|c|}{ ER+ Cases } & \multicolumn{2}{|c|}{ ER- Cases } \\
\hline & n $(\%)$ & OR $(95 \% \mathrm{CI})^{1}$ & n (cases) & OR $(95 \% \mathrm{CI})^{1}$ \\
\hline \multicolumn{5}{|l|}{ Age at menarche } \\
\hline$<12$ & $72(23.2)$ & $1[\mathrm{Ref}]$ & $13(21.0)$ & $1[\mathrm{Ref}]$ \\
\hline $12-13$ & $160(51.6)$ & $0.66(0.45,0.97)$ & $38(61.3)$ & $0.82(0.34,1.99)$ \\
\hline$\geq 14$ & $78(25.2)$ & $0.74(0.47,1.16)$ & $11(17.7)$ & $0.52(0.18,1.52)$ \\
\hline Continuous (1-year) & & $0.96(0.88,1.06)$ & & $0.87(0.70,1.10)$ \\
\hline$P_{\text {trend }}$ & & 0.46 & & 0.24 \\
\hline \multicolumn{5}{|l|}{ Age at 1st full-term pregnancy ${ }^{2}$} \\
\hline$<20$ & 47 (16.9) & $1.67(0.97,2.87)$ & $7(11.7)$ & $0.54(0.17,1.72)$ \\
\hline $20-24$ & $104(37.4)$ & $1[\mathrm{Ref}]$ & 25 (41.7) & $1[\mathrm{Ref}]$ \\
\hline $25-29$ & $71(25.5)$ & $1.17(0.76,1.79)$ & $14(23.3)$ & $0.78(0.32,1.88)$ \\
\hline $30+$ & $56(20.1)$ & $0.96(0.59,1.57)$ & $14(23.3)$ & $0.96(0.38,2.45)$ \\
\hline Continuous (1-year) & & $1.00(0.96,1.03)$ & & $0.99(0.93,1.06)$ \\
\hline$P_{\text {trend }}$ & & 0.79 & & 0.81 \\
\hline \multicolumn{5}{|l|}{ Number of full-term pregnancies } \\
\hline Nulliparous & $82(21.9)$ & $1[$ Ref $]$ & $14(17.7)$ & $1[\operatorname{Ref}]$ \\
\hline Parous & $292(78.1)$ & $0.98(0.72,1.34)$ & $65(82.3)$ & $1.09(0.54,2.19)$ \\
\hline 1 & $56(15.1)$ & $1.08(0.70,1.66)$ & 14(17.7) & $1.29(0.51,3.25)$ \\
\hline 2 & $112(30.3)$ & $0.84(0.59,1.20)$ & $27(34.2)$ & $0.93(0.42,2.05)$ \\
\hline$\geq 3$ & $120(32.4)$ & $1.09(0.75,1.58)$ & $24(30.4)$ & $1.18(0.52,2.71)$ \\
\hline \multicolumn{5}{|l|}{ Ever breast fed $^{2}$} \\
\hline No & $54(23.0)$ & $1[$ Ref $]$ & $18(35.3)$ & $1[\operatorname{Ref}]$ \\
\hline Yes & $181(77.0)$ & $0.89(0.58,1.35)$ & $33(64.7)$ & $0.35(0.14,0.87)$ \\
\hline \multicolumn{5}{|l|}{ Breast feeding duration (in months) ${ }^{2,3}$} \\
\hline Never & $54(23.2)$ & $1[\operatorname{Ref}]$ & $18(35.3)$ & $1[\operatorname{Ref}]$ \\
\hline$<6$ & $63(27.0)$ & $0.86(0.53,1.40)$ & $11(21.6)$ & $0.28(0.09,0.92)$ \\
\hline $6-12$ & $50(21.5)$ & $1.24(0.67,2.28)$ & $6(11.8)$ & $0.28(0.07,1.08)$ \\
\hline$>12$ & $66(28.3)$ & $0.63(0.36,1.09)$ & $16(31.4)$ & $0.54(0.16,1.79)$ \\
\hline Continuous (Per 6 months) & & $0.97(0.89,1.06)$ & & $0.99(0.87,1.14)$ \\
\hline$P_{\text {trend }}$ & & 0.47 & & 0.92 \\
\hline
\end{tabular}

Use of hormonal birth control in 2 years prior to 1st breast cancer diagnosis

$\begin{array}{lcccc}\text { No } & 339(92.4) & 1[\operatorname{Ref}] & 72(93.5) & 1[\operatorname{Ref}] \\ \text { Yes } & 28(7.6) & 1.00(0.59,1.67) & 5(6.5) & 1.06(0.34,3.31) \\ & & & & \\ \text { Menopause } & 4 \\ <45 & 48(19.2) & 1[\operatorname{Ref}] & 6(10.3) & 1[\operatorname{Ref}] \\ 45-49 & 62(24.8) & 0.55(0.31,0.99) & 12(20.7) & 0.87(0.21,3.56)\end{array}$


ER+ Cases

\begin{tabular}{|c|c|c|c|c|}
\hline & & \\
\hline & n $(\%)$ & OR $(95 \% \mathrm{CI})^{1}$ & n (cases) & OR $(95 \% \mathrm{CI})^{1}$ \\
\hline $50-54$ & $104(41.6)$ & $0.58(0.35,0.98)$ & $29(50.0)$ & $2.19(0.61,7.90)$ \\
\hline$\geq 55$ & $36(14.4)$ & $0.61(0.31,1.18)$ & $11(19.0)$ & $1.69(0.37,7.80)$ \\
\hline Continuous (1-year) & & $0.97(0.94,1.00)$ & & $1.04(0.96,1.13)$ \\
\hline$P_{\text {trend }}$ & & 0.06 & & 0.36 \\
\hline \multicolumn{5}{|l|}{ Current HRT use at 1st diagnosis 5} \\
\hline No & $142(55.7)$ & $1[$ Ref $]$ & $35(60.3)$ & 1 [Ref] \\
\hline Yes & $113(44.3)$ & $0.68(0.47,0.99)$ & $23(39.7)$ & $0.75(0.37,1.55)$ \\
\hline Current Estrogen & $65(25.5)$ & $0.72(0.47,1.11)$ & $14(24.1)$ & $1.02(0.45,2.30)$ \\
\hline Estrogen + Progestin & $48(18.8)$ & $0.63(0.40,1.00)$ & $9(15.6)$ & $0.47(0.17,1.25)$ \\
\hline
\end{tabular}

${ }^{1}$ Using conditional logistic regression, models were implicitly adjusted for the following matching factors: age, year of initial in situ breast carcinoma diagnosis, county of residence at diagnosis, surgical and radiation treatment, histology and grade of initial in situ breast tumor

2 Among parous women

${ }^{3}$ Adjusted for number of full-term pregnancies

${ }^{4}$ Among postmenopausal women

5 Among women who were postmenopausal prior to 1st diagnosis 